\title{
Clinical features of alcoholic suicide attempters/ non-attempters
}

\author{
Meena Agarwal and Keith Gaskell
}

\begin{abstract}
A cross-sectional study of 74 consecultive alcoholic patients admilted to a subreglonal alcohol treatment unit examines the socio-demographic and clinical dillerences between thoses who had/hod not attempled suicide, and investigates thetr reletionehipes to cument auicidat ideation. The suicide oftemplers were signiticantly younger, separated and unemployed. They began regular drinking earler, were more soverely dependent and had a hioher proportion of major depresilon, antisocial personatty disorder and another drug cbuse. The results suggest a high incidence of sulcidal behoviour in alcoholics and high poychiatilic comorbictity in alcoholics who attempt sulcide.
\end{abstract}

Alcoholic patients who attempt suicide form an important clinical group because of their utilisation of emergency medical services and subsequent risk of completed suicide (Roy \& Linnoila, 1986; Roy et al, 1990), but the nature of association between alcoholism and attempted suicide has been less researched (Black et al, 1986; Hawton et al, 1989; Roy et al, 1990; Platt \& Robinson, 1991). Clinical utility of a study of alcoholics who attempt suicide lies in identification and treatment of high risk groups.

Previous research suggested that, compared with non-attempters, the alcoholic suicide attempters were younger, began to drink earlier, were excesstve, problem and more severely dependent drinkers, reported increased family histories of alcoholism and affective disorder and more often had additional lifetime psychiatric diagnoses (Black et al, 1986; Hesselbrock et al, 1988; Roy et al, 1990).

While most American researchers have studied the connection between suicidal behaviour and alcoholism in populations of alcoholics, British researchers have studied this association in populations of suicide attempters. We conducted a study of alcoholics admitted to a subregional alcohol treatment unit, with and without previous suicide attempt(s). We believe that our study is the first report from a British alcohol treatment unit describing clinical features of alcoholics who had/had not attempted suicide. We designed a cross-sectional study measuring these patients' severity of alcohol dependence, depression and current suicidal ideation. We also measured the intercorrelations among variables related to suicidal tendencies.

Our aim was to compare suicide attempters and non-attempters in order to gain a wider understanding of the differences in their sociodemographic varlables, drinking history, psychiatric diagnoses and suicidal ideation. We also aimed to study the nature and patterns of reported suicide attempts. We hypothesised that alcoholic suicide attempters will have more profound psychopathology than non-attempters, and their severity of alcohol dependence, depression and number of previous suicide attempts will be correlated with suicidal ideation.

\section{The study}

The individuals in this study were referred to a subregional alcohol treatment unit in the northwest of England. The accepted referrals were made by local general practitioners, consultant psychiatrists and physicians, and the community drug and alcohol teams. Tertiary referrals from other districts in the region, were also accepted as this unit is a subregional specialist service.

We included 74 consecutive patients admitted for in-patient treatment between 1 August 1993 and 31 January 1994. All patients met DSM-III-R (American Psychiatric Association, 1987) criteria for alcohol dependence and gave informed consent for participation in the study. We divided them into two groups according to the presence or absence of history of previous suicide attempt(s). Suicide attempt was defined as an attempt at selfharm (Roy et al, 1990) by an individual at some time in his/her life. This included deliberate selfpoisoning and injury, when an individual deliberately causes self-injury and/or takes a substance in excess of any prescribed or generally recognised dosage (Kreitman, 1977).

Careful psychiatric histories, including social and personal history, drug and alcohol history, history of psychiatric lllness and nature and 
pattern of suicide attempts, were taken in a semistructured clinical interview. Questions based on DSM-III-R criteria were used for the assessment and diagnosis of antisocial personality disorder and another drug abuse. History of drug abuse included past and current drug abuse as reported by the patients and their referrers. Current mental state and physical examinations were carried out on admission and blood samples were taken to check mean corpuscular volume (MCV) and gammaglutamyl transpeptidase (GGT). We also used the following measurement instruments:

Short Alcohol Dependence Data (SADD) to measure the severity of alcohol dependence (Raistrick et al, 1983; Davidson \& Raistrick, 1986). It is a 15-item, forced choice, self-report scale designed to measure the range of present state alcohol dependence (total maximum score=45).

Beck's Depression Inventory (BDI; Beck et al, 1961) to measure the severity of depression. It is a 21-item self-report inventory covering a wide range of symptoms associated with depression (total maximum score=63).

Beck's Scale for Suicidal Ideation (SSI; Beck et al, 1979) to quantify the intensity of current suicidal thoughts of suicide attempters. This is a 19-item scale with each item worth 0-2 points generating a total score of 0-38.

\section{Statistical analysis}

We used $\chi^{2}$ test for categorical variables and twotailed Student's ' $t$ '-test for the comparison of means of continuous variables. Pearson correlation coefficients ( $r$ ) were calculated to investigate the relationships of alcohol dependence, depression and previous suicide attempts to current suicidal ideation and their significance was tested using the two-tailed ' $t$ '-test.

\section{Findings}

Of the total sample ( $n=74), 59 \%(n=44)$ of the alcoholic patients had attempted suicide. Eleven of the 16 females (69\%) and 33 of the 58 males (57\%) made suicidal attempts. Compared with non-attempters, the suicide attempters were younger $(P<0.05)$, maritally separated and long-term unemployed (Table 1).

A higher proportion of attempters than nonattempters reported family histories of alcoholism and depression (Table 1). They began regular drinking at an earlier age, had longer duration of problematic drinking, had been drinking excessively and had higher SADD scores, MCVs and GGT (Table 2). A significantly higher proportion of attempters than non-attempters had alcohol related problems, including drink related offences such as drink-driving convictions, and physical problems (Table 1). The significant physical problems included history of treatment for peptic ulcer $(P<0.025)$.

Significantly more attempters than non-attempters met DSM-III-R criterla for lifetime psychiatric diagnoses of major depression, antlsocial personality disorder and drug abuse (Table 1). The most frequently used drugs were cannabis, stimulants, hallucinogens and benzodiazepines. Significantly more attempters than nonattempters gave a history of previous in-patient alcohol treatment and past treatment with antidepressants (Table 1).

On index admission, the attempters had significantly higher BDI scores than non-attempters

Table 1. Significant differences between attempters and non-attempters

\begin{tabular}{|c|c|c|c|c|c|}
\hline \multirow[b]{2}{*}{ Variables } & \multicolumn{2}{|c|}{ Aftemplers $(n=44)$} & \multicolumn{2}{|c|}{ Non-attempters (n-30) } & \multirow[b]{2}{*}{ Signilicance $P$} \\
\hline & $n$ & (\%) & $n$ & (\%) & \\
\hline \multicolumn{6}{|l|}{ Demographic } \\
\hline separated & 10 & (23) & 1 & (3) & $<0.0001$ \\
\hline unemployed & 33 & (75) & 15 & (50) & $<0.05$ \\
\hline \multicolumn{6}{|l|}{ Family history } \\
\hline alcohollsm & 27 & (61) & 12 & (40) & $<0.05$ \\
\hline depression & 8 & (18) & 2 & (7) & $<0.025$ \\
\hline \multicolumn{6}{|l|}{ Drink related problems } \\
\hline Offences & 30 & (68) & 13 & (43) & $<0.025$ \\
\hline physical & 34 & (77) & 16 & (53) & $<0.05$ \\
\hline \multicolumn{6}{|l|}{ DSM-III-R diagnoses } \\
\hline major depression & 22 & $(50)$ & 2 & (7) & $<0.0001$ \\
\hline drug abuse & 21 & (48) & 7 & (23) & $<0.005$ \\
\hline antisocial personallty disorder & 18 & (41) & 6 & (20) & $<0.005$ \\
\hline \multicolumn{6}{|l|}{ Previous treatment } \\
\hline alcohol treatment & 33 & (75) & 15 & (50) & $<0.05$ \\
\hline antidepressants & 29 & (66) & 7 & (23) & $<0.0001$ \\
\hline Hopelessness & 9 & (20) & 1 & (3) & $<0.0001$ \\
\hline
\end{tabular}


Table 2. Alcohol history: continuous variables

\begin{tabular}{lccl}
\hline Vartables & $\begin{array}{c}\text { Aftemplers (n-44) } \\
\text { Moan (s.d.) }\end{array}$ & $\begin{array}{l}\text { Non-attempters (n-30) } \\
\text { Moan (s.d.) }\end{array}$ & $\begin{array}{l}\text { Signilicance } \\
\boldsymbol{p}\end{array}$ \\
\hline Age began regular drinking (years) & $15.5(2.4)$ & $19.1(5.0)$ & $<0.002$ \\
Duration of problem drinking (years) & $13.9(7.7)$ & $9.1(6.4)$ & $<0.01$ \\
Average consumption per week (units)' & $233.5(128.0)$ & $163.1(103.0)$ & $<0.02$ \\
SADD score & $29.2(7.5)$ & $23.3(8.3)$ & $<0.01$ \\
MCV & $97.9(5.8)$ & $93.2(6.9)$ & $<0.01$ \\
GGT & $145.3(115.1)$ & $87.5(91.5)$ & $<0.02$ \\
\hline
\end{tabular}

1. One unit represents $8 \mathrm{~g}$ of alcohol as contained in half a pint of beer, a standard glass of wine and a single measure of spirtt.

Table 3. Pearson Product Moment correlation (D) among various variables in alcoholic sulcide attempters $(n=44)$

\begin{tabular}{llll}
\hline & BDI & SSI & SADD \\
\hline Previous attempts & $+0.33^{\circ}$ & $+0.42^{* \cdots}$ & +0.12 \\
BDI & & $+0.33^{\circ}$ & $+0.38^{* \cdots}$ \\
SSI & & & $+0.48^{\cdots \cdots}$ \\
\hline
\end{tabular}

- $P=<0.05 ; \cdots P=<0.01: \cdots P=0.002$.

BDI: Beck's Depression Inventory; SSI, Beck's Scale for Sulcidal Ideation; SADD, Short Alcohol Dependence Data.

$(P<0.002)$ and a higher proportion reported feeling hopeless (Table 1). Thirty per cent of the attempters, as compared to none of the nonattempters, reported suicidal ideation on BDI. The mean SSI score of the attempters was 10.93 (s.d.=4.82). Twelve of the $44(27 \%)$ attempters had made single attempts and $32(73 \%)$ were repeated attempters. The mean number of their previous attempts was 3.43 (s.d. $=2.49$ ). The significant positive correlates of SSI were the number of past attempts, SADD scores and BDI scores (Table 3 ).

The most frequently used method of suicide attempt was self-poisoning (90\%); $45 \%$ used self-cutting of which $7 \%$ used self-cutting alone and the remainder $(38 \%)$ used it in combination with other methods, most frequently overdose. Other methods involved self-stabbing by one patient, self-shooting by one and attempted drowning by another. The most frequently used drug for overdose was paracetamol. Seventythree per cent of the attempters reported hospitalisation following suicide attempts. However, only two of the 44 attempters reported treatment in intensive care following an overdose. Ninety-seven per cent of the attempters reported alcohol consumption just before or at the time of attempting suicide. The most frequently reported precipitant was arguing with spouse/partners. Seventy-two per cent of the attempters reported making impulsive attempts.

\section{Comments}

The present study replicates the findings of previous studies of alcoholics entering treatment (Hesselbrock et al, 1988; Roy et al, 1990). Similar to Berglund's study (1984) of suicidal alcoholics, we also found that a higher proportion of attempters than non-attempters had a history of peptic ulcer. Our results were similar to Beck et als (1982) findings of strong correlations between depression, past suicide attempts and current suicidal ideation. However, we found that scores for alcohol dependence were also significantly correlated to current suicidal ideation, and there was a significant correlation between BDI and SADD scores. This may suggest that severely dependent alcoholics may also have had secondary/coexistent depression. The presence of current suicidal ideation reemphasises Beck's (1982) comment:

"the finding that alcoholic suicide attempters were also currently thinking about suicide, cautions that the alcoholics entering treatment should be closely observed for suicide risk."

However, the most striking finding was a much higher rate of attempted suicide among alcoholics than reported in previous studies (17\% to $29.2 \%$, Hesselbrock et al, 1988; Roy et al, 1990). A number of factors may have operated to account for this. The unit's admission policies and the referral patterns may have an influence on characteristics of the sample population. Our subjects were the most severely dependent and problem drinkers, referred to a specialist treatment facility. It is also recognised that the people in the northwest are amongst the heaviest drinkers in England with higher than national average rates for psychiatric admissions and have increased morbidity (North Western Regional Health Authority, 1990). Our definition of attempted suicide led us to include patients with varying degrees of suicidal intent. However, the majority of the attempters (36 of the 44) reported a moderately high suicidal intent while making 
previous attempts and only eight patients denied any serious intent.

The reported patterns of suicide attempts were similar to previous studies, in terms of selfpoisoning being the most frequent method (Hawton et al, 1989), increased utilisation of medical services (Roy et al, 1990) and the attempts generally being not too serious (Black et al, 1986). However, we found that the most frequently used drug for overdose was paracetamol, whereas in his study of suicide attempters with a history of alcoholism Hawton et al (1989) reported most frequent use of tranquillisers and sedatives. An explanation for our finding of most frequent use of paracetamol for overdose could be its easy availability, without the need for a prescription. Our attempters also used sedatives and hypnotics but less frequently than paracetamol. This could also be explained in terms of a ready availability, as a high proportion of our attempters were misusing benzodiazepines. Although a high proportion of attempters were treated with antidepressants in the past, the use of antidepressants for overdose was less frequently reported. This could result from a policy of prescribing short supplies at any one time to prevent suicide, and the problem of availability of antidepressants due to the need for a prescription. Similar to Hawton et ails report (1989) a very high proportion of our attempters reported drinking alcohol just prior to or at the time of making attempts, possibly to enhance courage and reduce pain.

Black et al (1986) suggested that alcoholism, depression and antisocial personality disorder may predispose to suicide attempts and the interaction of the three is particularly dangerous. This model could be applied to our patients as we also found that a high proportion of our attempters were severely dependent and chronic drinkers, had major depression and antisocial personality disorder and a high incidence of suicidal behaviour. We also found that a high proportion were misusing another drug, which may be an additional risk factor for suicide attempts.

Despite methodological limitations, for example a small size and selective nature of the study sample, our results confirm the findings of previous investigators including a high incidence of suicidal behaviour among alcoholics entering treatment, and the high psychiatric comorbidity and current suicidal ideation in alcoholic suicide attempters. Clinicians should be aware of high risk factors for suicide attempts in alcoholics admitted for in-patient treatment. Treatment and prevention programmes should include earty interventions and treatment of alcohol problems, post treatment relapse prevention strategies and maintenance of abstinence, vigorous treatment of depression and treatment and rehabilitation of drug misusers.

\section{References}

AMERICAN PSYCHIATRIC Association (1987) Dlagnostic and Statistical Manual of Mental Disonders (3rd edn, revised) (DSM-III-R). Washington, DC: APA.

Beck. A. T., WARD, C. H., Mendelson, M., et al (1961) An inventory for measuring depression. Archives of General Psychiatry, 4, 561-567.

- Kovacs, M. \& Weissman, A. (1979) Assessment of suicidal intention: the scale for suicidal ideation. Joumal of Consulting and Clinical Psychology, 47, 343-352.

- STEER, R. A. \& MCELROY, M. G. (1982) Relationships of hopelessness, depression and previous suicide attempts to suicidal ideation in alcoholics. Journal of Studies in Alcohol, 43. 1042-1046.

BERGLUND, M. (1984) Suicide in alcoholism. Archives in General Psychiatry. 41, 888-891.

BLACK, D. W., YATES, W., PETTY, F., et al (1986) Suicidal behaviour in alcoholic males. Comprehenstue Psychiatry. 27. 227-233.

DAVIDSON, R. \& RAISTRICK, D. (1986) The validity of the Short Alcohol Dependence Data (SADD) Questionnaire: a short self report questionnaire for the assessment of alcohol dependence. British Joumal of Addiction, 81, 217-222.

HAWTON, K. FAGG, J. \& MCKEOWN, S. P. (1989) Alcoholism. alcohol and attempted suicide. Aloohol and Alcoholism. 24. 3-9.

Hesselbrock, M., Hesselbrock. V., Syzmansk, K., et al (1988) Suicide attempts and alcoholism. Journal of Studies in Alcohol 49, 436-442.

KRETMAN, N. (ed.) (1977) Parasudcide. London: John Wiley. NORTH WESTERN REGIONAL HEALTH AUTHORTY (1990) Aloohol Misuse in the North Westem Region: a Proflle. Manchester: NWRHA.

PLATT, S. \& ROBINSON, A. (1991) Parasuicide and alcohol: a 20 year survey of admissions to a Regional Polsoning Treatment Centre. International Journal of Soctal Psychiatry. 37, 159-172.

RAISTRICK, D., DUNBAR, G. \& DAVIDSON, R. (1983) Development of a qustionnaire to measure alcohol dependence. Brttish Joumal of Addiction, 78, 89-95.

RoY, A. \& LINNOIL, M. (1986) Alcoholism and suicide. Suictde and Life Threatening Behavior. 16. 244-273.

- LAMPARSK, D.. DEJONG, J., et al (1990) Characteristics of alcoholics who attempt suicide. American Joumal of Psychiatry, 147, 761-765.

Meena Agarwal, Senior Registrar, Fleming Nuffield Unit, Burdon Terrace, Jesmond, Newcastle upon Tyne; Keith Gaskell, Consultant Psychiatrist. Lancaster Moor Hospital, Lancaster

Correspondence: Dr Meena Agarwal, 46 Larkhill Cottages, Old Langho, Blackburn BB6 8AR 